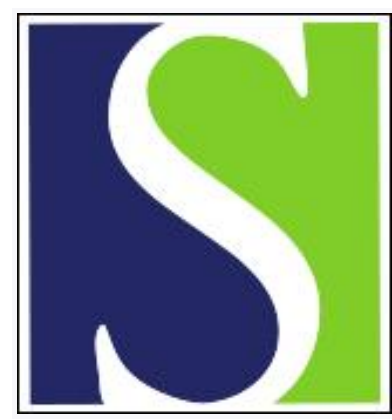

Scand J Work Environ Health 2019;45(4):386-395

https://doi.org/10.5271/sjweh.3801

Published online: 24 Jan 2019, Issue date: 01 Jul 2019

The effect of strengthening health literacy in nursing homes on employee pain and consequences of pain - a stepped-wedge intervention trial

by Larsen AK, Thygesen LC, Mortensen OS, Punnett L, Jørgensen MB

To our knowledge this is the first study introducing workplace health literacy to reduce pain. This feasible and effective intervention shifted the overall mean pain level downwards. Organizing health literacy in nursing homes might enable building work environment efforts targeting the needs of employees. Prospects of organizing health literacy in other workplace settings and targeting other health challenges should be investigated.

Affiliation: National Research Centre for the Working Environment, Lersø Parkallé 105, Copenhagen, Denmark. akl@nrcwe.dk

Key terms: employee pain; health literacy; intervention; nursing home; organization; pain; sick leave; sickness absence; stepped-wedge intervention trial; worker; workplace

This article in PubMed: www.ncbi.nlm.nih.gov/pubmed/30677126 


\title{
The effect of strengthening health literacy in nursing homes on employee pain and consequences of pain - a stepped-wedge intervention trial
}

\author{
by Anne Konring Larsen, PhD, ${ }^{12}$ Lau Caspar Thygesen, PhD, ${ }^{2}$ Ole Steen Mortensen, PhD, ${ }^{3,4}$ Laura Punnett, PhD, ${ }^{5}$ Marie Birk \\ Jørgensen, $P h D^{1}$
}

\begin{abstract}
Larsen AK, Thygesen LC, Mortensen OS, Punnett L, Jørgensen MB. The effect of strengthening health literacy in nursing homes on employee pain and consequences of pain - a stepped-wedge intervention trial. Scand J Work Environ Health. 2019;45(4):386-395. doi:10.5271/sjweh.3801
\end{abstract}

Objective This study examined the effectiveness of a workplace health literacy intervention on pain intensity, bothersomeness of pain, and sickness absence.

Methods The quasi-experimental stepped-wedge cluster trial evaluated an intervention with two elements: (i) courses for employees and management to organize a joint foundation of knowledge about pain prevention and management with communication tools, and (ii) structured dialogs between employee and supervisor, to develop action plans to prevent and reduce pain. Monthly measurements were taken of pain intensity ( $0-10$ scale), bothersomeness (days/month), and pain-related absence (days/month).

Results Six workplaces were recruited, and $88 \%$ of employees (509) participated in evaluations. At baseline, mean pain level was 4.0, mean bothersomeness was 3.8 days/month, and mean pain-related absence was 0.6 days/month. From linear mixed models, pain intensity was reduced by $-0.28[95 \%$ confidence interval (CI) $-0.52--0.04]$ corresponding to a $7 \%$ reduction. For employees with pain $>3$ at baseline, the reduction was -0.74 $(95 \%$ CI $-1.11--0.38)$ or $12 \%$. There was no significant mean change in bothersomeness or sickness absence among all employees.

Conclusion This intervention was both feasible and effective in shifting the overall mean pain level downwards for the entire population by $7 \%$, with an accentuated effect among employees with pain levels $>3$. Organizing health literacy in nursing homes might be a feasible and effective way to build work environment efforts targeting the needs of employees. Future studies should investigate whether organizing health literacy is effective in other workplace settings and for employees with other health challenges.

Key terms organization; sickness absence; sick leave; worker; workplace.

Musculoskeletal pain is an extensive societal problem with wide-ranging consequences both for the individual and the society $(1,2)$. Pain is especially prevalent among low-income workers and particularly those with physically demanding work (1-4). The combination of pain and physically demanding work increases the risks of poor quality of life, work disability, sickness absence, and early retirement $(2,5-9)$.

In Danish nursing homes, several initiatives have been introduced to improve the working environment (10). Despite these efforts, nursing aides still report heavy lifting, high physical and emotional work demands, and high prevalence of pain in muscles and joints $(11,12)$. Limited effectiveness of previous initiatives could be explained by the multiple factors that contribute to the development and persistence of pain (13). However, introducing an intervention targeting multiple factors concurrently is complex to implement, time-consuming, often expensive for the workplace, and requires high employee motivation (14).

Program implementation is a recognized challenge both in workplace studies and practical settings, espe-

1 National Research Centre for the Working Environment, Copenhagen, Denmark.

2 National Institute of Public Health, University of Southern Denmark, Copenhagen, Denmark.

3 Department of Occupational and Social Medicine, Copenhagen University Hospital, Holbæk, Denmark.

4 Section of Social Medicine, Department of Public Health, University of Copenhagen, Copenhagen K, Denmark.

5 Center for the Promotion of Health in the New England Workplace, University of Massachusetts Lowell, Lowell MA, USA. mark. [E-mail:aala.tl.dk] 
cially with initiatives involving low-income employees (15-19). Limited formal education and knowledge about fundamental health issues have been associated with lower participation in workplace studies $(20,21)$. Also, insufficient organizational structures for prevention and health at the workplace and inadequate communication in the organization hamper implementation $(22,23)$.

Both individual abilities and the capacities of the workplace are encompassed in the concept of "health literacy," which entails an individual's ability to access, understand, appraise and apply health information and the capacity of their surroundings to provide accessible, understandable, appraisable and applicable health information (24). Targeting health literacy in the workplace setting, therefore, would address challenges both in the individual worker's ability to prevent and handle pain and the organization's capability to support employees to do so. Previous efforts to improve individual health literacy have primarily targeted patients and their ability to navigate the healthcare system (25). Introducing health literacy as a tool for improving the work environment and work-related health is a new approach to workplace interventions $(26,27)$.

We have developed a conceptual model for health literacy in the workplace, which highlights the role of interpersonal (eg, support from and knowledge-sharing with colleagues and supervisor) and organizational factors (eg, structures for communication about work environment and pain) to support workers' ability and action in the work environment (28). We developed a simple intervention consisting of knowledge-building (courses) and structured communication (dialogs) to improve workplace health literacy at multiple levels of an organization.

The aim of this study was to examine the effectiveness of this organizational intervention to strengthen workplace health literacy in nursing homes. The specific goals were to reduce employee pain (primary outcome of the study) as well as the frequency with which employees are affected by pain in their work (bothersomeness) and take sick leave (two important secondary outcomes).

\section{Methods}

We conducted a quasi-experimental stepped-wedge cluster trial. The stepwise design with repeated measurements of the outcomes allows for clusters to cross over from control to intervention at specific time points (29).

\section{Study population}

We aimed to recruit a single municipality with as many nursing homes as possible so as to include the whole organization: employees, supervisors and managers at the nursing homes as well as representatives from the municipality, including the responsible director general of health and care.

We used a three-stage recruitment plan. The first stage was to contact the directors general of health and care in 27 out of the 98 municipalities in Denmark with information about the intervention's aim and content. They were requested to recruit all nursing homes in their municipality. The director general was also requested to participate in steering group meetings and include the implementation of the intervention in the management goals.

In the second stage, we met with representatives from the municipality and all of its nursing homes to present the aims and content of the intervention. The recruitment effort sought their support for an organizational approach; that is, that all activities should happen during paid work hours, with compulsory attendance, and all employees would be eligible to participate in the evaluation.

The final stage was to have local meetings - at those nursing homes that agreed to participate under these conditions - to inform the employees. Important information to convey to participants was that participation was an organizational decision so that all intervention activities would happen as a part of the work routines, but that individual participation in the evaluation (questionnaires and interviews) was voluntary.

Nursing home employees were primarily nurses' aides who were either trained social- and health-service aides or helpers (1-2 years of vocational training). The managers were primarily registered nurses. Other employees were kitchen, cleaning and technical staff. Whether temporary staff should participate in the intervention was up to the manager at each workplace to decide.

The Danish Data Protection Agency approved the trial (Journal number 2014-38/28350-3), which was reported to the local ethical committee (Protocol H-12013 FSP). The trial was conducted in accordance with the Helsinki Declaration.

\section{The intervention}

A steering committee was established including representatives from each nursing home, the municipality, the local union representative in the municipality, and two researchers. Its purpose was to assist in planning the intervention, share knowledge during its implementation, and contribute to the evaluation afterwards.

Initially, a formative evaluation of each workplace was conducted in collaboration with the local health and safety committees to tailor the intervention to the needs at each workplace. Thereafter, two initial courses of three hours each were held for managers and employees separately; both initial courses were based on cognitive 
behavioral training. The delivery of the courses was guided by a written protocol describing the content, structure and aim of each of the four different courses (first and second course each for employees and management) (28). The objective for the employees' courses was to strengthen knowledge and competencies to access, understand, process and assess information from the organization about the work environment as well as musculoskeletal pain and its consequences. The primary course elements were strategies for prevention of muscle pain, coping with pain at work, and tools for improving communication with colleagues and management about health and work. The primary focus in the courses for managers was on how to recognize, understand, and handle employees with pain, and tools for communication and action. The courses were held in small groups to facilitate openness and constructive communication between colleagues. Three-hour "booster" courses were held in every facility after six months.

The next step was implementation of a structured dialog between each supervisor and his or her employees about work environment challenges and health. Supervisors were responsible for scheduling the dialog approximately every third week. The dialog followed a guide provided on an electronic tablet, which asked employees about their main challenges at work and requested a plan for improvement. Topics were unrestricted to ensure that a relevant dialog could be held for all employees, with or without pain. We sought to generate a space where the employees felt comfortable to discuss work and health-related challenges. Further, we sought to provide the supervisor with tools for facilitating a constructive dialog focused on identifying current work or health challenges for each employee; using knowledge from the courses to identify possible solutions; and generating a plan for specific, realistic and effective actions. The employee and supervisor were each asked to rate the degree of completion of the plan from the previous dialog $(0-10$ scale) .

In collaboration with employee representatives at each workplace, there were communications (posters, meeting announcements, e-mails) to remind employees and supervisors about course content and motivate them to continue the dialogs.

\section{Data collection}

The primary outcome was musculoskeletal pain intensity and the secondary outcomes were "bothersomeness" and self-reported sickness absence. We collected outcome data through text messages every four weeks during and after the evaluation period. At each time point, the respondents received three questions on pain intensity, frequency of bothersomeness, and pain-related sickness absence, each referencing the past four weeks.
Employees hired during the trial period entered the intervention and the evaluation onwards but naturally did not contribute baseline information.

Pain was measured as highest intensity of pain in the muscle and joints (30). The question posed was "On a scale from $0-10$, what was the highest intensity of pain in your muscles and joints? $(0=$ no pain, $10=$ worst imaginable pain)" (31). The bothersomeness question asked: "How many days did pain in muscle and joints affect your work routines? (Answer with a number from 0-28)" (31). Pain-related sickness absence was measured with: "How many days have you been absent from work because of pain in muscles and joints? (Answer with a number from 0-28)" (32).

Employee course attendance was registered by the instructors. Completed dialogs were registered on the tablet. Numbers of dialogs per employee, along with numbers of courses held and course attendees, were examined as measures of implementation. Information about organizational baseline characteristics, workforce size, and employee age, sex and seniority (years working at the specific nursing home) were based on de-identified employee lists from the workplaces.

\section{Statistical analysis}

We used SAS version 9.4 (SAS Institute Cary, NC, USA) for statistical analysis. All analyses of outcomes followed the intention to treat, including all enrolled participants as well as employees joining during the evaluation. The intervention effect was estimated using linear mixed models, in order to use data from all time points for the sites that had started the intervention as well as the sites that had not yet been exposed (controls) at any time point (33). Mixed models take account of clustering of observations of employees within groups, as well as the correlation of repeated measurements within participants $(34,35)$. The outcomes were compared between three different phases of the intervention: (i) the control phase (before the intervention), (ii) during the intervention ( $0-5$ months), and (iii) after the intervention (6-12 months). We included intervention as a categorical variable and a random intercept for nursing home. We tested whether calendar time (years 2013-2016) was significantly associated with the outcomes (34, 36-38). Further we investigated five possible confounders (age, sex, seniority, season and nursing home) by adding these to the model one at a time. The criterion for retention was whether adding the variable changed the size of the coefficient for the primary independent variable by $\geq 15 \%$. Model assumptions were tested by confirming the normality of residuals for pain, bothersomeness, and sickness absence for each intervention phase (1-3).

To examine whether baseline pain level might influence the effect of the intervention (floor effect), we 
conducted separate analysis among employees with pain $>3$ at baseline. Additionally, a sensitivity analysis on employees with $\geq 2$ measurements in each period (control, during and after) was conducted.

We compared demographic and pain characteristics between participants who dropped out and completers, and between responders with response rates to the text message questionnaires below $60 \%$ and $60 \%$ and above.

\section{Results}

We recruited one municipality which agreed to host a preliminary meeting with representatives from each nursing home. Eight nursing homes were represented at the meeting, six of which decided to participate in the intervention. Just before the start of evaluation, one nursing home dropped out. Another nursing home dropped out after one year of evaluation, following their baseline measurement. To ensure an adequate sample size, we then recruited one of the remaining nursing homes within the same municipality as well as one from another municipality. The first six nursing homes were recruited in September 2013 and the last two in September 2014 (figure 1).

The time of crossover from control to intervention was determined for each nursing home in an agreement between management and researchers for practical and logistical reasons. Pre-intervention observation ranged from 1-14 measurements and 6 post measurements were used (figure 1). The nursing home that dropped out after one year of evaluation contributed time only in the control state. Baseline measures were initiated between October and December 2013 in five nursing homes and in November 2014 in the two nursing homes recruited later.

In the participant flowchart (figure 2), nursing homes are aligned according to the phases of evaluation (before baseline and during and after intervention), although the actual time points for each nursing home were staggered. The employee lists showed 482 employees from seven nursing homes at baseline. Excluding those in temporary employment, and those refusing to participate in the evaluation, 424 (88\%) were enrolled. The workplace that withdrew from the project just after baseline removed 47 employees. An additional 140 employees dropped out individually at various points, most frequently for leaving employment (81 participants, $58 \%$ of the dropouts). Stating they no longer wanted to participate, 42 employees $(30 \%)$ withdrew from the project, and 17 (12\%) dropped out due to maternity leave, other leave, or educational programs.

All employees enrolled in the evaluation $(\mathrm{N}=424)$, including those joining during the evaluation $(\mathrm{N}=92)$, were included in the analyses $(\mathrm{N}=516)$ except for those who never answered the questionnaires $(\mathrm{N}=7)$, resulting in 509 participants.

The number of managers at the nursing homes varied between 3-8. Five nursing homes had changes in management during the evaluation; one of these replaced the top manager (table 1). The facility workforces ranged from 43-89 employees, $75 \%$ of which were aides.

At each nursing home, $75-90 \%$ of employees participated, and baseline characteristics were available for $83 \%$. The mean employee age was 47 years, $89 \%$ were women, and mean seniority was 5 years. These characteristics were similar among the nursing homes, despite small differences in gender distribution (82-96\% female). Also there was variability in baseline mean pain intensity (2.8-5.0), frequency of bothersomeness (2.5-4.7 days), and pain-related absence (0.1-1.3 days).

There were only small differences in baseline characteristics between participants who dropped out and

\begin{tabular}{|c|c|c|c|c|c|c|c|c|c|}
\hline \multirow{2}{*}{$\begin{array}{c}\text { Nursing } \\
\text { home }\end{array}$} & Year 1 & \multicolumn{4}{|c|}{ Year 2} & \multicolumn{4}{|c|}{ Year 3} \\
\hline & $\begin{array}{l}\text { Quarter } \\
4\end{array}$ & $\begin{array}{l}\text { Quarter } \\
1\end{array}$ & $\begin{array}{l}\text { Quarter } \\
2\end{array}$ & $\begin{array}{l}\text { Quarter } \\
3\end{array}$ & $\begin{array}{l}\text { Quarter } \\
4\end{array}$ & $\begin{array}{l}\text { Quarter } \\
1\end{array}$ & $\begin{array}{l}\text { Quarter } \\
2\end{array}$ & $\begin{array}{l}\text { Quarter } \\
3\end{array}$ & $\begin{array}{l}\text { Quarter } \\
4\end{array}$ \\
\hline 7 & & & & & & & & & \\
\hline 6 & & & & & & & & & \\
\hline 5 & & & & & & & & & \\
\hline 4 & & & & & & & & & \\
\hline 3 & & & & & & & & & \\
\hline 2 & & & & & & & & & \\
\hline 1 & & & & & & & & & \\
\hline
\end{tabular}

Figure 1. The stepped-wedge design of the intervention and how workplaces stepped into the invention at different time points. The light grey color indicated control time, the darkest grey indicates the intervention period ( $0-5$ months) and the hatched cells indicate the time following the intervention (6-12 months). 
completers (table 2). Employees who dropped out on average were three years younger and had two years less job seniority. Completers had a slightly higher proportion of women, slightly higher frequency of bothersomeness, and lower sickness absence.

Of the participants $55 \%$ answered $\geq 60 \%$ of the questionnaires. Their characteristics differed little from those who provided $<60 \%$ of the measurements (table 3 ).

\section{Implementation}

A total of 101 courses were held at the nursing homes, of which 58 were initial courses for employees. The initial courses were held between 3-9 times at each nursing home. Mean participation in the initial employee courses was $79 \%$ of the facility workforce (range $61-96 \%$ ). For managers, the mean participation was $71 \%$, ranging from $50-100 \%$.

During the intervention period, a total of 2055 dialogs between employees and their supervisors were held. The number of dialogs per employee varied between $1-16$ (mean 4). On average, $48 \%$ of the planned dialogs were held, ranging from $23-107 \%$ (107\% means more dialogs were held than were required).

The steering committee for the six nursing homes in the same municipality met every six months as intended. One representative (work environment representative, supervisor or top manager) from each nursing home, the Director of Health and Care, a local work environment consultant from the municipality, and a local union representative participated. A total of six steering committee meetings were held before, during and after the intervention. At the nursing home located in a separate municipality, local meetings were held with the local occupational health and safety group at the same intervals.

\section{Effect of the intervention on pain, bothersomeness and pain-related sickness absence}

In the models for pain, only calendar time met the criterion for inclusion. In the models for bothersomeness and pain-related sickness absence, calendar time, age, seniority and nursing home met the inclusion criterion. However age and seniority were correlated (Spearman $\mathrm{r}=0.32, \mathrm{P}<0.001)$; therefore we included only time, seniority and nursing home.

\section{Effect of the intervention on pain}

The effect of the intervention on pain intensity among all employees, adjusted for time, was a reduction of -0.28 [ $95 \%$ confidence interval (CI) $-0.52--0.04]$ after the intervention (6-12 months) compared with the control phase (table 4). There was no significant effect during the intervention.

Among employees with baseline pain levels $>3$, we found an estimated reduction in pain of $-0.74(95 \%$ CI $-1.11--0.38$ ) and a tendency to pain reduction during the intervention of -0.27 (95\% CI $-0.61-0.06)$. All

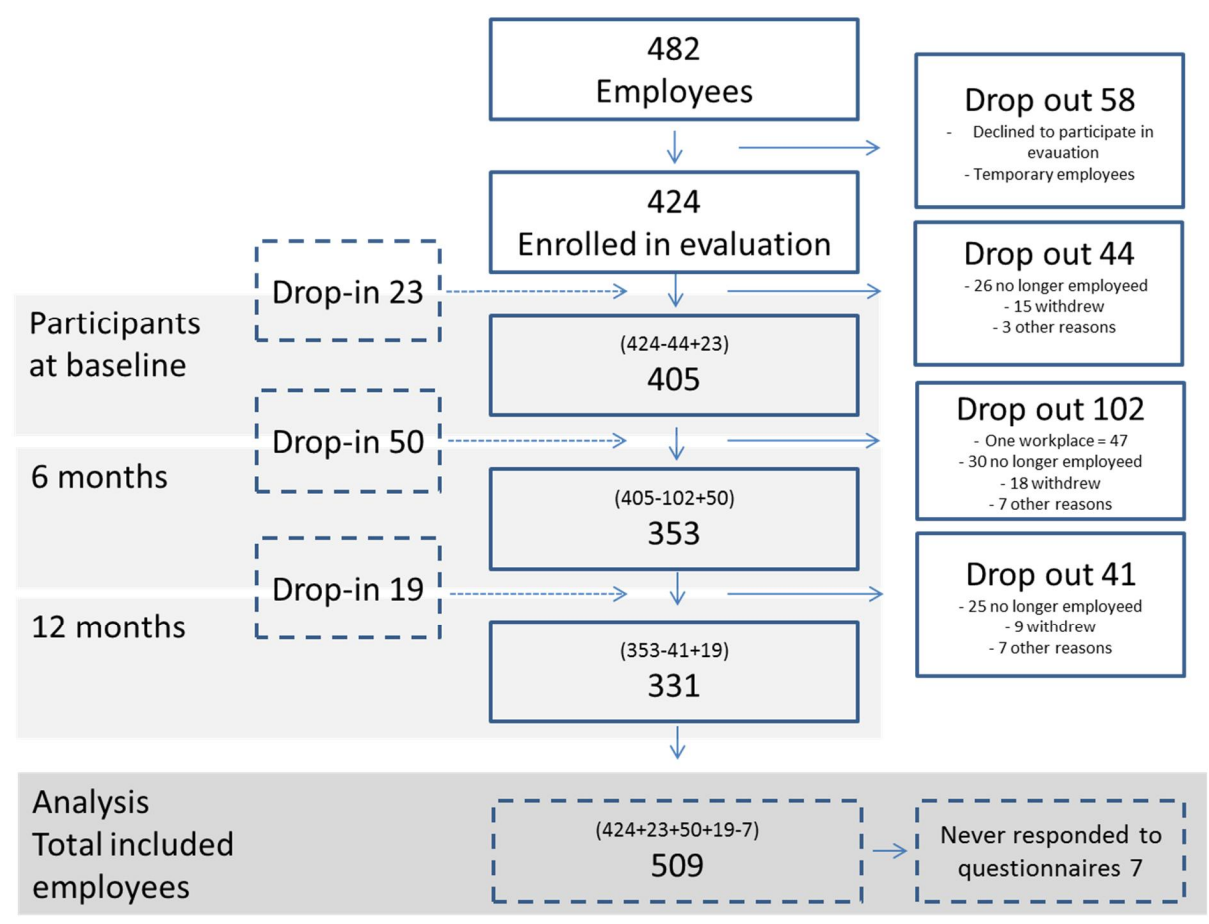

Figure 2. Flowchart of participants. Of the 482 employees at the workplaces, 424 enrolled in evaluation and 92 "dropped in". In total 509 employees were included in the analysis. 
Table 1. Characteristics of organization, the employees and participation in intervention activities across the seven nursing homes.

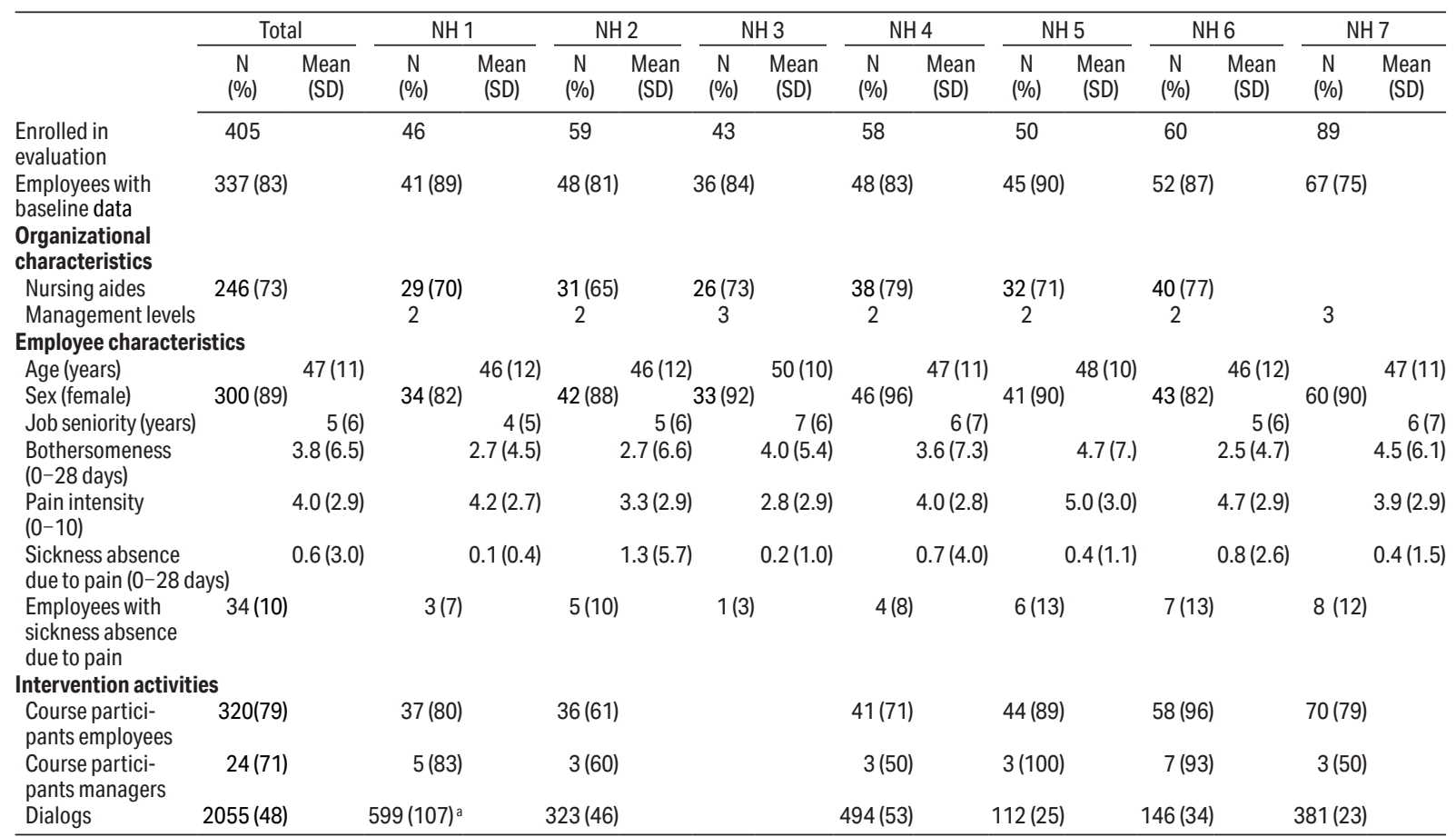

a $107 \%$ means that on average they held dialogs more often than required. Seniority is measured as years at present workplace.

Table 2. Comparison of baseline characteristics between drop-outs and completers. [SD=standard deviation.]

\begin{tabular}{|c|c|c|c|c|c|c|}
\hline & \multicolumn{3}{|c|}{ Drop-out ( $\mathrm{N}=143)$} & \multicolumn{3}{|c|}{ Completers $(\mathrm{N}=331$} \\
\hline & Mean & SD & $\%$ & Mean & SD & $\%$ \\
\hline Age (years) & 45 & 13 & & 48 & 10 & \\
\hline Sex (female) & & & 83 & & & 91 \\
\hline Job seniority, years (current) & 4 & 6 & & 6 & 7 & \\
\hline Bothersomeness (days/month) & 3.4 & 6.2 & & 3.9 & 6.5 & \\
\hline Pain intensity (0-10 scale) & 4.0 & 2.9 & & 4.0 & 3.0 & \\
\hline Sickness absence (days/month) & 0.8 & 4.5 & & 0.5 & 2.2 & \\
\hline
\end{tabular}

employees who had at least two measurements in each phase had an estimated reduction after the intervention of -0.41 (95\% CI -0.72- -0.09).

\section{Effect of the intervention on bothersomeness}

There was no overall effect of the intervention on bothersomeness after the intervention. Among employees with pain $>3$ at baseline, there was a tendency toward less bothersomeness after the intervention $[-1.01$ (95\% CI -2.14-0.11)] (table 4).

\section{Effect of the intervention on sickness absence}

There was no overall effect of the intervention on employee sickness absence [-0.22 (95\% CI - $0.57-0.14)]$.
Table 3. Comparison of baseline characteristics between employees with response rates $</>60 \%$. [SD=standard deviation.]

\begin{tabular}{|c|c|c|c|c|c|c|}
\hline & \multicolumn{3}{|c|}{ Response rate $\leq 60 \%$} & \multicolumn{3}{|c|}{ Response rate $>60 \%$} \\
\hline & Mean & SD & $\%$ & Mean & SD & $\%$ \\
\hline Age (years) & 45 & 12 & & 48 & 11 & \\
\hline Sex (female) & & & 87 & & & 91 \\
\hline Job seniority, years (current) & 3 & 5 & & 7 & 7 & \\
\hline Bothersomeness (days/month) & 4.1 & 7.0 & & 3.6 & 6.3 & \\
\hline Pain intensity (0-10 scale) & 4.1 & 2.9 & & 3.9 & 3.0 & \\
\hline Sickness absence (days/month) & 0.8 & 3.6 & & 0.5 & 2.6 & \\
\hline
\end{tabular}

Among employees with pain score $>3$ there was a reduction in sickness absence of 0.65 days (95\% CI $-1.23-$ -0.07) (table 4).

\section{Discussion}

To our knowledge this is the first organizational intervention to strengthen health literacy in nursing homes by introducing knowledge-building and structures for communication. This intervention reduced the intensity of muscle/joint pain among participating employees. After a 6-month intervention, the mean reduction in pain intensity among all employees was -0.28 on a scale from $0-10$, corresponding to approximately $7 \%$ 
Table 4. Results of the effect of the intervention on pain intensity, bothersomeness and pain-related sickness absence on all employees and employees with pain intensity $>3$. [SD=standard deviation.]

\begin{tabular}{|c|c|c|c|c|c|c|c|c|c|c|}
\hline \multirow{7}{*}{$\begin{array}{l}\text { Pain intensity (0-10) } \\
\text { Control } \\
\text { During } \\
\text { After (6-12 months) }\end{array}$} & \multicolumn{5}{|c|}{ All employees, adjusted for time $(\mathrm{N}=509)$} & \multicolumn{5}{|c|}{ Employees with pain $>3$, adjusted for time $(\mathrm{N}=187)$} \\
\hline & Mean & SD & Estimate & $95 \% \mathrm{Cl}$ & P-value & Mean & SD & Estimate & $95 \% \mathrm{Cl}$ & P-value \\
\hline & \multirow{4}{*}{4.0} & \multirow{4}{*}{2.9} & & & & \multirow{4}{*}{6.3} & \multirow{4}{*}{1.8} & & & \\
\hline & & & & & & & & & & \\
\hline & & & -0.05 & $-0.28-0.18$ & 0.69 & & & -0.27 & $-0.61-0.06$ & 0.11 \\
\hline & & & & $-0.52--0.04$ & 0.02 & & & -0.74 & $-1.11--0.38$ & $<0.0001$ \\
\hline & \multicolumn{5}{|c|}{$\begin{array}{l}\text { All employees, adjusted for time, } \\
\text { seniority and nursing home ( } N=402)\end{array}$} & \multicolumn{5}{|c|}{$\begin{array}{l}\text { Employees with pain }>3 \\
\text { adjusted for time, seniority and nursing home }(\mathrm{N}=136)\end{array}$} \\
\hline & Mean & SD & Estimate & $95 \% \mathrm{Cl}$ & P-value & Mean & SD & Estimate & $95 \% \mathrm{Cl}$ & P-value \\
\hline \multicolumn{11}{|c|}{ Bothersomeness ( $0-28$ days) } \\
\hline Control & 3.8 & 6.5 & & & & 6.3 & 7.6 & & & \\
\hline During & & & 0.42 & $-0.32-1.16$ & 0.26 & & & 0.01 & $-1.04-1.06$ & 0.99 \\
\hline After (6-12 months) & & & 0.03 & $-0.75-0.81$ & 0.94 & & & -1.01 & $-2.14-0.11$ & 0.08 \\
\hline \multicolumn{11}{|c|}{ Sickness absence ( $0-28$ days) } \\
\hline Control & 0.6 & 3.0 & & & & & & & & \\
\hline During & & & -0.13 & $-0.47-0.21$ & 0.45 & & & -0.34 & $-0.89-0.21$ & 0.22 \\
\hline After (6-12 months) & & & -0.22 & $-0.57-0.14$ & 0.23 & & & -0.65 & $-1.23--0.07$ & 0.03 \\
\hline
\end{tabular}

below baseline. This could represent both improvements among employees with pain as well as possible prevention of incident pain among pain-free employees. Among employees with baseline pain $\geq 3$, the reduction was -0.74 , corresponding to $12 \%$. This implies that the larger part of the effect may have been for those who began with some musculoskeletal pain.

This feasible intervention was characterized by low required resources for implementation because it was carried out during work hours and did not require that the workplaces call in extra personnel.

Participation in courses was relatively high $(79 \%$ of employees and $71 \%$ of managers). Implementation of the dialogs was generally lower $(48 \%$ of the planned dialogs were held). If the dialogs had been held more consistently, there might have been an even higher benefit to workers. Examining the implementation process will be valuable for uncovering obstacles to the dialogs, and in particular what factors influenced the reluctance or failure of the supervisors to schedule the dialogs.

The courses were based on cognitive behavioral training, which has previously given a positive effect on pain intensity among patients (39) and in a working population of nursing aides (14). We included all employees in the analysis, including those who were pain-free at baseline $(22 \%)$, and the baseline mean pain level was relatively low (4.0). Previous interventions to reduce pain have often specifically selected individuals (patients or employees) with pain at baseline (40).

A previous study on nursing aides showed that employees with pain $\geq 3-5$ had an increased risk of painrelated sickness absence (6). Further, when pain levels were near the thresholds, even small reductions in pain intensity could decrease the risk of long term sickness absence considerably (6). It is possible that a larger sample size in this study could have resulted in clearer results regarding the effect on pain-related sickness absence, in the group of employees with pain levels $>3$.

Some studies have found an effect of workplace interventions on bothersomeness although these were mainly group-based interventions $(14,41)$. It is possible that more emphasis on group elements in this study (for example, more involvement of colleagues in developing plans and taking action) would have been more effective on bothersomeness. Concerning pain-related sickness absence, communication between management and employees regarding pain has previously shown to be effective among employees at high risk of sickness absence (40). This is in line with the findings of the sensitivity analyses of our study, showing that employees with baseline pain above 3 had significantly reduced sickness absence.

In a previous study on this population (baseline data) we found limited manager awareness of employee pain and managers frequently reporting inadequate competence to handle employees with pain (42). These findings support the idea that strengthening employee and manager competence, and communication about work environment and health, are essential elements to increase awareness and facilitate relevant action from both managers and employees. Whether other approaches to knowledgebuilding and communication could be more efficient to reduce employee pain remains to be investigated.

\section{Strengths and limitations}

In contrast to most workplace interventions, we used an organizational approach to introduce a simple intervention with such limited time requirements that it could be normalized in the daily routine. Previous workplace studies have had very low individual-level participation between $25-50 \%$ of employees participating (43). In this study, $88 \%$ of employees were enrolled and participated in the evaluation at least once. 
The organizational approach enabled a joint focus on the individual and the organization, building structures for knowledge-sharing and communication in the organization while following up on the individual level. This allows for each employee to reflect on her/his work environment challenges and get continued support from the organization to take relevant action. Thus the intervention is relevant for employees both with and without pain. It also implies potential sustainability within the organization after the research activities have ceased.

The organizational approach implied a dynamic study population, allowing participants to enter the evaluation during the intervention period (after baseline). The relatively high employee turnover at the nursing homes could have affected the estimates of the effects. If employees leaving the workplace and thus not contributing follow-up information did so due to pain, the effect could have been overestimated (44). However, our analyses of baseline pain in those who dropped out and those who completed the study suggest that this was not the case.

Another consideration is whether and how quickly employees who started at the workplace after baseline profited from the intervention. If the intervention had the anticipated system-wide effect (strengthening organizational health literacy) immediately, then it may have affected employees entering during the evaluation. However, it is possible that an effect takes some time to become manifest. Thus longer intervention and follow-up periods might have generated more encouraging results.

In practice-based, public health research, randomization is not always feasible or logistically possible and therefore the importance of identifying the best design for each specific trial has been emphasized (45). The steppedwedge designs have methodological strengths compared with other quasi-experimental design options. The design enabled all nursing homes to participate and allowed for repeated measurements on the same individuals before, during and after $(33,37)$, thereby strengthening the ability to draw conclusions. A risk of the quasi-experimental stepped-wedge design is the potential source of confounding from calendar time $(33,37,38)$. We included clusterspecific random components to allow for separation of intervention and time effects.

A drawback of the stepped-wedge design is that the evaluation design can be prolonged, increasing the risk of employee turnover during the evaluation and employee fatigue in answering questions, both of which might lead to more missing data (36). However, in this study employees answered on average $80 \%$ of all questionnaires.

A general challenge in the analysis of bothersomeness and pain-related sickness absence is the floor effect. Employees reported a mean of 3.8 out of 28 days with bothersomeness at baseline and only approximately $10 \%$ of them reported pain-related sickness absence in the last month.

\section{Concluding remarks}

This intervention to strengthen health literacy by building knowledge and structured communication was effective in shifting the overall mean pain level downwards for the entire population in six nursing homes, with accentuated effect among employees with starting pain level $>3$. The intervention required a minimum of time and resources by workplaces; while the overall effect on the population was numerically small, the intervention might still be cost-effective to the workplaces over time. Thus, organizing health literacy might be a feasible and effective way to build work environment efforts targeting the needs of employees in nursing homes, and perhaps in other sectors also.

\section{Acknowledgement}

The Danish Working Environment Research Fund financed this study (journal number 20130069210).

\section{Conflicts of interest}

The authors declare no conflicts of interest.

\section{References}

1. Mortensen OS, Andersen JH, Ektor-Andersen J, Eriksen HR, Fallentin N, Frost P et al. Hvidbog om sygefravær og tilbagevenden til arbejde ved muskel- og skeletbesvær. Årsager og handlemuligheder [Sickness absence and return to work with musculoskeletal disorders. Causes and options for action]. Copenhagen: The National Research Center for the Working Environment; 2008.

2. McDonald M, DiBonaventura M, Ullman S. Musculoskeletal pain in the workforce: the effects of back, arthritis, and fibromyalgia pain on quality of life and work productivity. J Occup Environ Med 2011 Jul;53(7):765-70. https://doi. org/10.1097/JOM.0b013e318222af81.

3. Genebra CV, Maciel NM, Bento TP, Simeão SF, Vitta A. Prevalence and factors associated with neck pain: a population-based study. Braz J Phys Ther 2017 Jul - Aug;21(4):274-80. https://doi.org/10.1016/j. bjpt.2017.05.005.

4. Valat JP, Goupille P, Védere V. Low back pain: risk factors for chronicity. Rev Rhum Engl Ed 1997 Mar;64(3):189-94.

5. Jørgensen MB, Nabe-Nielsen K, Clausen T, Holtermann A. Independent effect of physical workload and childhood socioeconomic status on low back pain among health care workers in Denmark. Spine 2013 Mar;38(6):E359-66. https://doi.org/10.1097/BRS.0b013e31828435d4. 
6. Andersen LL, Clausen T, Burr H, Holtermann A. Threshold of musculoskeletal pain intensity for increased risk of longterm sickness absence among female healthcare workers in eldercare. PLoS One 2012;7(7):e41287. https://doi. org/10.1371/journal.pone.0041287.

7. Burr H. Arbejdsmiljø i Danmark 2005: Et overblik fra den Nationale Arbejdsmiljøkohorte [Work environment in Denmark 2005. Overview of the Danish Work Environment Cohort Study]. København: Arbejdsmiljøinstituttet; 2006.

8. George SZ, Fritz JM, Bialosky JE, Donald DA. The effect of a fear-avoidance-based physical therapy intervention for patients with acute low back pain: results of a randomized clinical trial. Spine 2003 Dec;28(23):2551-60. https://doi. org/10.1097/01.BRS.0000096677.84605.A2.

9. Holtermann A, Clausen T, Aust B, Mortensen OS, Andersen LL. Does occupational lifting and carrying among female health care workers contribute to an escalation of pain-day frequency? Eur J Pain 2013 Feb;17(2):290-6. https://doi. org/10.1002/j.1532-2149.2012.00175.x.

10. The National Research Center for the Working Environment. Virksomhedernes Arbejdsmiljø 2012 [Organizational Work Environment 2012]. København: Det Nationale Forskningscenter for Arbejdsmiljø; 2014.

11. The National Research Center for the Working Environment. Work Environment and Health in Denmark 2012. København. Det Nationale Forskningscenter for Arbejdsmiljø; 2013.

12. Verhagen AP, Bierma-Zeinstra SM, Burdorf A, Stynes $\mathrm{SM}$, de Vet HC, Koes BW. Conservative interventions for treating work-related complaints of the arm, neck or shoulder in adults. Cochrane Database Syst Rev 2013 Dec;(12):CD008742.

13. Burton AK, Balagué F, Cardon G, Eriksen HR, Henrotin Y, Lahad A et al.; COST B13 Working Group on Guidelines for Prevention in Low Back Pain. Chapter 2. European guidelines for prevention in low back pain : November 2004. Eur Spine J 2006 Mar;15 Suppl 2:S136-68. https:// doi.org/10.1007/s00586-006-1070-3.

14. Rasmussen CD, Holtermann A, Bay H, Søgaard K, Birk Jørgensen M. A multifaceted workplace intervention for low back pain in nurses' aides: a pragmatic stepped wedge cluster randomised controlled trial. Pain 2015 Sep;156(9):1786-94. https://doi.org/10.1097/j.pain.0000000000000234.

15. Grosch JW, Alterman T, Petersen MR, Murphy LR. Worksite health promotion programs in the U.S.: factors associated with availability and participation. Am J Health Promot 1998 Sep-Oct;13(1):36-45. https://doi. org/10.4278/0890-1171-13.1.36.

16. Robroek SJ, van Lenthe FJ, van Empelen P, Burdorf A. Determinants of participation in worksite health promotion programmes: a systematic review. Int J Behav Nutr Phys Act 2009 May;6:26. https://doi.org/10.1186/1479-5868-6-26.

17. Rongen A, Robroek SJ, van Lenthe FJ, Burdorf A. Workplace health promotion: a meta-analysis of effectiveness. Am J Prev Med 2013 Apr;44(4):406-15. https://doi.org/10.1016/j. amepre.2012.12.007.
18. Gerdle B, Brulin C, Elert J, Eliasson P, Granlund B. Effect of a general fitness program on musculoskeletal symptoms, clinical status, physiological capacity, and perceived work environment among home care service personnel. J Occup Rehabil 1995 Mar;5(1):1-16. https://doi.org/10.1007/ BF02117816.

19. Aittasalo M, Miilunpalo S. Offering physical activity counselling in occupational health care -- does it reach the target group? Occup Med (Lond) 2006 Jan;56(1):55-8. https://doi.org/10.1093/occmed/kqi191.

20. Devraj R, Herndon CM, Griffin J. Pain awareness and medication knowledge: a health literacy evaluation. J Pain Palliat Care Pharmacother 2013 Mar;27(1):19-27. https:// doi.org/10.3109/15360288.2012.751955.

21. Shelton RC, Goldman RE, Emmons KM, Sorensen G, Allen JD. An investigation into the social context of lowincome, urban Black and Latina women: implications for adherence to recommended health behaviors. Health Educ Behav 2011 Oct;38(5):471-81. https://doi. org/10.1177/1090198110382502.

22. Durlak JA, DuPre EP. Implementation matters: a review of research on the influence of implementation on program outcomes and the factors affecting implementation. Am J Community Psychol 2008 Jun;41(3-4):327-50. https://doi. org/10.1007/s10464-008-9165-0.

23. Jørgensen MB, Villadsen E, Burr H, Punnett L, Holtermann A. Does employee participation in workplace health promotion depend on the working environment? A cross-sectional study of Danish workers. BMJ Open 2016 Jun;6(6):e010516. https://doi.org/10.1136/bmjopen-2015-010516.

24. Sørensen K, Van den Broucke S, Fullam J, Doyle G, Pelikan J, Slonska Z et al.; (HLS-EU) Consortium Health Literacy Project European. Health literacy and public health: a systematic review and integration of definitions and models. BMC Public Health 2012 Jan;12:80. https://doi. org/10.1186/1471-2458-12-80.

25. Berkman ND, Sheridan SL, Donahue KE, Halpern DJ, Crotty K. Low health literacy and health outcomes: an updated systematic review. Ann Intern Med 2011 Jul;155(2):97-107. https://doi.org/10.7326/0003-4819-1552-201107190-00005.

26. Sørensen K, Brand H. Health literacy--a strategic asset for corporate social responsibility in Europe. J Health Commun 2011;16 Suppl 3:322-7. https://doi.org/10.1080/10810730.2 011.606072 .

27. Wong BK. Building a health literate workplace. Workplace Health Saf 2012 Aug;60(8):363-9. https://doi. org/10.1177/216507991206000806

28. Larsen AK, Holtermann A, Mortensen OS, Punnett L, Rod $\mathrm{MH}$, Jørgensen MB. Organizing workplace health literacy to reduce musculoskeletal pain and consequences. BMC Nurs 2015 Sep;14:46. https://doi.org/10.1186/s12912-015-00964.

29. Hussey MA, Hughes JP. Design and analysis of stepped wedge cluster randomized trials. Contemp Clin 
Trials 2007 Feb;28(2):182-91. https://doi.org/10.1016/j. cct.2006.05.007.

30. Deyo RA, Battie M, Beurskens AJ, Bombardier C, Croft $\mathrm{P}$, Koes B et al. Outcome measures for low back pain research. A proposal for standardized use. Spine 1998 Sep;23(18):2003-13. https://doi.org/10.1097/00007632199809150-00018.

31. Dionne CE, Dunn KM, Croft PR, Nachemson AL, Buchbinder R, Walker BF et al. A consensus approach toward the standardization of back pain definitions for use in prevalence studies. Spine 2008 Jan;33(1):95-103. https:// doi.org/10.1097/BRS.0b013e31815e7f94.

32. Burdorf A, Post W, Bruggeling T. Reliability of a questionnaire on sickness absence with specific attention to absence due to back pain and respiratory complaints. Occup Environ Med 1996 Jan;53(1):58-62. https://doi.org/10.1136/ oem.53.1.58.

33. Huynh AK, Lee ML, Farmer MM, Rubenstein LV. Application of a nonrandomized stepped wedge design to evaluate an evidence-based quality improvement intervention: a proof of concept using simulated data on patient-centered medical homes. BMC Med Res Methodol 2016 Oct;16(1):143. https://doi.org/10.1186/s12874-0160244-x.

34. Woertman W, de Hoop E, Moerbeek M, Zuidema SU, Gerritsen DL, Teerenstra S. Stepped wedge designs could reduce the required sample size in cluster randomized trials. J Clin Epidemiol 2013 Jul;66(7):752-8. https://doi. org/10.1016/j.jclinepi.2013.01.009.

35. Twisk JW. Applied multilevel analysis: a practical guide: Cambridge University Press; 2006.

36. Barker D, McElduff P, D’Este C, Campbell MJ. Stepped wedge cluster randomised trials: a review of the statistical methodology used and available. BMC Med Res Methodol 2016 Jun;16:69. https://doi.org/10.1186/s12874-016-0176-5

37. Handley MA, Schillinger D, Shiboski S. Quasi-experimental designs in practice-based research settings: design and implementation considerations. J Am Board Fam Med 2011 Sep-Oct;24(5):589-96. https://doi.org/10.3122/ jabfm.2011.05.110067.
38. Hemming K, Taljaard M, Forbes A. Analysis of cluster randomised stepped wedge trials with repeated crosssectional samples. Trials 2017 Mar;18(1):101. https://doi. org/10.1186/s13063-017-1833-7.

39. Linton SJ, Boersma K, Jansson M, Svärd L, Botvalde M. The effects of cognitive-behavioral and physical therapy preventive interventions on pain-related sick leave: a randomized controlled trial. Clin J Pain 2005 Mar-Apr;21(2):109-19. https://doi.org/10.1097/00002508200503000-00001

40. Linton SJ, Boersma K, Traczyk M, Shaw W, Nicholas M. Early workplace communication and problem solving to prevent back disability: results of a randomized controlled trial among high-risk workers and their supervisors. J Occup Rehabil 2016 Jun;26(2):150-9. https://doi.org/10.1007/ s10926-015-9596-z.

41. Frederiksen P, Indahl A, Andersen LL, Burton K, HertzumLarsen R, Bendix T. Can group-based reassuring information alter low back pain behavior? A cluster-randomized controlled trial. PLoS One 2017 Mar;12(3):e0172003. https://doi.org/10.1371/journal.pone.0172003

42. Larsen AK, Falkenstrøm S, Jørgensen MB, Rod MH The role of managers in addressing employees with musculoskeletal pain: a mixed methods study. Int Arch Occup Environ Health 2018 Apr;91(3):361-72. https://doi. org/10.1007/s00420-017-1284-1.

43. Jørgensen MB, Villadsen E, Burr H, Mortensen OS, Holtermann A. Does workplace health promotion in Denmark reach relevant target groups? Health Promot Int 2015 Jun;30(2):318-27. https://doi.org/10.1093/heapro/ dat041.

44. Bell ML, Kenward MG, Fairclough DL, Horton NJ. Differential dropout and bias in randomised controlled trials: when it matters and when it may not. BMJ 2013 Jan;346:e8668. https://doi.org/10.1136/bmj.e8668.

45. Bonell CP, Hargreaves J, Cousens S, Ross D, Hayes R, Petticrew $\mathrm{M}$ et al. Alternatives to randomisation in the evaluation of public health interventions: design challenges and solutions. J Epidemiol Community Health 2011 Jul;65(7):582-7. https://doi.org/10.1136/jech.2008.082602.

Received for publication: 19 March 2018 